\title{
Experiential attunements in an illuminated city at night: a pedagogical writing experiment
}

\author{
Zhang V., Kelly D., Rodriguez Castro L., Edensor T., Lobo M., Adamczyk E., Barry K., Bissell \\ D., Buckle C., Dorignon L., Hughes A., Iaquinto B. L., Kennedy M., McKay C., Ratnam C. \& \\ Wolifson, P.
}

\begin{abstract}
This article traces stories of singular footsteps taken on a collective meandering through Brisbane city, as a pedagogical experiment in writing for geographers. The diverse encounters recounted here took place as part of an extended workshop on the topic of light, beginning with an afternoon discussion, and ending in an evening walk through the illuminated city. This paper aims to do two things through the example of light: firstly, it explores the experiential attunements enacted in the event by resonating practices of talk with practices of movement, speculating on the enablements afforded by the conditions of the workshop. Secondly, presenting a range of writing that emerged out of this passage from world to word, this article is a performance of the diverse translations necessary to writing attunement. Refracted through an extended introduction by the event organisers, the vignettes that emerged from the day are then presented as something of a virtual walk in themselves: speaking to the entangled histories of the event, our bodies, and Brisbane city. Key Words: attunement, light, method, creative experiment, urban.
\end{abstract}

\section{INTRODUCTION: AN EXPERIMENT}

\author{
Vickie Zhang, The University of Melbourne \\ David Kelly, Deakin University \\ Laura Rodriguez Castro, Griffith University
}

This paper is a pedagogical experiment in writing that derives its insights from practices of walking, attuning and thinking with light. It is also a playful piece that aims to map an incomplete and dynamic "affective cartography” (McCormack 2008, 419) of a Brisbane cityscape bursting with experiential possibilities, apprehending "the relation between atmosphere and bodies." Within, the reader will find a diversity of narratives - embodied and reflective - that have been assembled as a collaborative product of the Cultural Geography Study Group of the Institute of Australian Geographers. Through attempts to experiment with 'writing differently', the stories aim 
to capture the myriad ways in which light afforded encounters that pulled bodies into exchange with urban forms. Our event, we argue, aimed to foster new competencies with and dispositions towards ‘writing the earth’ creatively in geographic practice (Cameron 2012, Springer 2018).

More specifically, this collaborative article records the experiences of scholars at a workshop entitled Aesthetics, Anxieties and Atmospheres: Illuminated Urban Nightscapes presented by Tim Edensor. To set the scene: twenty-five geographers met on $31^{\text {st }}$ July 2017, a balmy mid-winter's afternoon in sub-tropical Brisbane, a day before the annual conference of the Institute of Australian Geographers. The mood was jovial; most of us had flown, trained and bussed ourselves in that morning, carrying a hint of the logistic lethargy of orienting in a new place. With many coming from the more temperate cities, the warmth of the tropical winter sun offered invigorating respite from the southern cold.

Our shared target in the workshop was illumination, tying into recent concerns with light and illumination in human geography and across the humanities and social sciences (Morris 2011; Edensor 2017b; Kumar 2015; Edensor and Bille 2017; Edensor and Sumartojo 2018; Bille and Sørensen 2007; Isenstadt, Petty and Neumann 2015; Pink and Sumartojo 2017). We had planned for the workshop to be an extended exercise in creative attunement. We would talk about light in the afternoon, in a setting of scholarly inquiry - a seminar room at a university - and then follow this talking by walking with light in the evening, as sunlight fades and city lights flicker on. What we sought to evoke was an attunement to light through the readings and workshop, and an invigorated attentiveness to illumination in the walk.

Inviting attending geographers to enact more attentive modes of engaging with light, our event aimed to activate a space for enacting creative methods of working and writing, sensitive that disciplinary shifts demand the acquisition and development of new embodied competencies. Like others working under the loose rubric of the geohumantities, our paper shares an interest in a zone where geographers draw upon styles of inquiry in the humanities that are creatively enhanced by a spatial attention. We explore this mode of thinking and doing, where scholars and practitioners unite, and ponder what it might offer our geographic research practices (Hawkins et al. 2015). In presenting our vignettes, we aim to consider what might need to be acquired to undertake research attunements with a creative ethos, counter to practices of aesthetic evaluation and judgement - a decision we further justify in following paragraphs. Our introduction aims instead at a provisional mapping of the event. Rather an analysis of the content of the stories that follow, this introduction's 
objective is to elucidate the process through which these texts emerged, with the aim to speculate on what the event's creative invitation might have offered us as academic geographers.

As Madge (2014, 180) asks of creative practice in the context of poetry: "Is poetry a creative process of thoughtful making, an act of expressing new and imaginative ideas and feelings that can be undertaken by anyone, or is it an aesthetic practice that can only be performed by those with particular skills or formal training?” ${ }^{1}$ In this paper, we attune specifically to the geographic possibilities of the former: thinking with the dual capacities of lighting and writing as aids in the creative process of expression. As such, the provocation of 'creativity' was mobilised in a particular way: as the invitation to break usual academic conventions of presentation, attentive that how and in what way this sensibility stretches will manifest differently to each author (Marston and Leeuw 2013). Thus, the pieces presented below vary in their writerly ambit: from casual conversations to melancholic meditations, from didactic exposition to impressionistic composition.

The range of affective tenors related by the texts perhaps reflects the 'ordinariness' of urban lighting, a habitualised phenomenon ubiquitous in contemporary lives. Urban illumination might be seen as a 'merely interesting' (Ngai 2012) object: something which - although meriting attention as an object of curiosity - is "underpinned by a calm, if not necessarily weak, affective intensity” (Ngai 2012, 113). Of course, 'merely interesting' need not mean inert, or devoid of potential. Indeed, emerging literatures on light are attentive to the flat-affective backgrounds against which illumination gains its potential to "reenchant space by defamiliarizing habitually apprehended surroundings” (Edensor and Sumartojo 2018, 112). Edensor and Sumartojo write of the ways light projection art "can create new ways of perceiving our familiar urban environments that can prompt us to reimagine our surroundings, their histories, and affective experiences” (2018, 112). This paper enacts a similar, if more modest, experiment with the interruptive potential of light. It is centred not just on light, but more specifically with the rather more banal experience of illumination in the city at night.

Our focus on light emanates from an understanding of it as a force that mediates the way we interact with the world. As Edensor (2017a, 16) notes, the curation and experience of light "solicits particular sensory, perceptual, affective, epistemological and imaginative engagements.” Attunement through the practice of walking with light shares in Stengers's $(2005,994)$ proposal that our encounters with our environments change in the way we receive our world and open up an "opportunity to arouse a slightly different awareness" of spaces that "provoke thought." 
Accordingly, we work with a style of creativity that draws on Williams's (2016) acknowledgement the creative agency of matter itself, moving beyond the assumption of a foundational 'creative' individual. We follow Stewart $(2007,5)$ in positioning the aim of the project, through encounters with light, as something "to create a contact zone for analysis" rather than suspend moments to conceptual scruitiny. Our workshop was therefore not just an event of thinking about space and light, but, rather, a practice in working with light to engender alternative lines along which to encounter the city. However, the encounters we enact here traverse not so much the 'spectacular' of curated events, but rather the far more quotidian 'taken for granted' circumstances of everyday urban illumination in an Australian capital city (Pink and Sumartojo 2017): of street lights as they emerge with the setting sun, of spotlights shining across the dense flora of public parks, of car headlamp strings at peak hour linking the city to the suburbs. Accordingly, through the example of illumination, we ground the role of attunement as a primary force of attachment of people to place and follow the contention, that " $[\mathrm{t}] \mathrm{o}$ attune is to tune in or to tune out; it is to calibrate our bodies as instruments” (Brigstocke and Noorani 2016, 2)

The workshop itself was divided into three parts. Firstly, a month before the event, three readings were circulated on different dimensions of light. The second part was the workshop session itself, meeting in the afternoon at the University of Queensland's lush St. Lucia campus. For the postgraduate students sitting around the table, this was the first time many of us had met. The session began with a presentation by Tim Edensor that moved across light, dark, staged illuminations, differential attunements and cultural ways of seeing. This was followed by a diverse question-and-answer format that took us far away from the prescribed texts and themes, and back again. Then, with exhaustion following exhilaration, we took a quick break to retreat, before reassembling near the city at South Brisbane station. All that remained was the third part of the workshop - a walk through Brisbane city nightscapes. From the train station, we haphazardly split into groups - some larger, some smaller - or embarked on individual routes. Our aim was to wander around the city freely while reflecting on the questions that had emerged from the day, before meeting again for dinner in two hours’ time.

\section{Method play}

Our approach to this paper draws upon our collective pre-occupation with method in human geography, and a desire to explore how researchers might nurture spaces where anticipations of place become re-orientated toward the unfamiliar. Our discussion explores how different situational awarenesses might facilitate sensitivities which postpone tendencies of paranoid 
evaluation, thereby engendering new potentials of attunement; we begin by allowing ourselves, in this case, to be directed by the oft-backgrounded force of light. Rather than centering the usual toolkit for navigating strange cities, such as maps and local knowledges, we focussed instead on a framework for participants to attune to the affectivity and sensuality of light in the illuminated city. We engaged participants, therefore, in a workshop that aimed to precondition ethnographic dispositions to undertake what Swanton $(2010,2337)$ calls "purposeful drifts" that deviate from a normal objective research agenda, with a commitment to the exploration of shared embodied experiences rather than normative, 'skilled' or critically distant engagement within academic practice. In this section, we describe the workshop as an event that 'primes' our bodies (Bissell 2010); we centre walking as a method of re-inscribing the city with meaning (Roy and Roy 2018) and outline the themes of the creative contributions that substantiate our experience of light.

A pre-conference workshop is a prime opportunity to engage in conceptually-driven and empirically-grounded collaborative work. As conferences are often held in unfamiliar places for a majority of participants, such settings provide a distinctive contingency for scholars to meet up and test out emerging trajectories of thought and inquiry. Inspired by Latham and McCormack's (2009) non-representational vignettes and Cook et al.’s (2016) experimental session format and conference writing, we invited participants to write about their different experiences with light on the walk in 500 words, emphasising descriptive rather than analytical contributions and creative modes of writing. Emphasising the productive filtrations of sensory mediums, participants were encouraged to work with different technologies on the walk, such as sound, image and video (a selection of which are shown in Figures 1, 2, 3 \& 4). Although we had stressed open-endedness leading into the event, to give some structure post factum, we suggested a provisional question that participants might respond to in their vignettes, although we underscored that this was not coercive: What qualities of illuminated spaces facilitate the emergence of new registers for knowing about the city?

We brought these pieces together, as a written performance of the walk's many experiential departures. It would be, we rationalised, a small experiment. Acknowledging that writing is also a way of thinking and a mode of sense-making (DeLyser 2010, Crang 2010), writing through the event became a way of tracking something of the passages of experience, registering those things that particularly strike us between reading-discussing-walking-writing. Our writing task posed a methodological question, stimulated by Stewart's suggestion that we should take "descriptive detours" so as "to pull academic attunements into tricky alignment with the amazing, sometimes eventful, sometimes buoyant, sometimes endured, sometimes so sad, always commonplace labour 
of becoming sentient to a world's work” $(2011,445)$. Asking participants to resist the temptation to conceptualise, textual engagements with their urban encounters instead provide a semblance of the sensations and variations of walking through the illuminated city at night. Drawing out nonrepresentational provocations, we were interested in capturing something of the movements of thought provoked by the sensorium in the moment, short-circuiting the autonomic jump to meaning-making and habits of interpretation.

Critical here is the notion of walking as an elementary experience of the city. As an embodied experience, walking attunes the body to become attentive to the affective and sensory life of the city drowning in illumination. de Certeau (1984, 93 emphasis in original) characterises walkers as “Wandersmänner, whose bodies follow the thicks and thins of a [...] 'text' they write without being able to read it." As a "blind and opaque mobility" (ibid, 93), to walk in and with the city at night is to make sense of it without the normativity of a day-time ocular grammar. Instead, walking in Brisbane at night prompts an awareness of the affective interface between landscape and body. The body and the city are constantly re-inscribed with shape, form and meaning through encounters that conjure a sense of continual change. Yet, qualities of movement and experience do not come as pre-written texts, but rather, as always-emerging embodied forms whose transformation into text always requires an act of translation. Indeed, “[n]ot too long ago, writing in the discipline proceeded through a naive realism and was considered an objective and unproblematic process wherein words were thought to link thoughts with objects in irrefutable ways” (Springer 2017, 1). Instead, there is now a widespread recognition across geography of the contingency of writing, that writing is as much about the 'world' as it is about the writer's disposition towards her object. This shifts an emphasis towards the status of the writing as a creative act, a contingent calcification. Stewart (2012) notes that: "writing is not epiphenomenal to thought but its medium. As it sidles up to worlds, disparate and incommensurate things throw themselves together. As it attunes, spatial and temporal dimensions come into play” (518). Stewart intimates here a productive moment: as we write, we don't just evoke and describe existing objects of analysis, we are also creating new qualitative forms, accruing new depths of association.

\section{Storied experience}

Writing and the literary have become central places for experimentation with form, pluralising our genres of research-presentation in geography (see, e.g. Cameron 2012; Hawkins 2015; Magrane 2015; Anderson, 2018). In asking participants for vignettes of their experiences, we sought a storied experience of the event. Like Stewart's understanding of writing as a creative opening, 
Rose (2016) suggests that the potential of stories lies in the origins they both acknowledge and inaugurate. Rose argues that the telling of stories in research should not be thought of as evidence - empirics used in the service of a grand theory - but as ethical acts which reveal the origins of thought,disclose the utter reliance of the researcher on their encounters with others and by acknowledging the shared origins of our work,thus recognise the distributed ownership of the thought that emerges. Whereas reliance on pre-established narratives are seen to mark the 'end' of thought through their desensitising tendencies, Rose asserts that stories tell the beginning of thought: as the "gift" from which all research must begin (140). There is a minor difference of emphasis worth noting in the ethics of writing that Rose and Stewart respectively articulate in these texts: whereas Rose (2016) is making an argument for the communicative potential of the story as a passage or connector, Stewart (2011) mobilises writing more broadly as a pedagogical tool for the rendering of the space, an endeavour of onto-epistemological value even prior to its instrumentalisation towards a narrative. However, both approaches to ethnographic storytelling accord with movements in cultural geographic writing towards "micrologies", accounts which reveal not through the grandness of abstraction, but via the specificity of the small detail (Philo 2017). The stories of the event in which we participated similarly aspire to this Janus-faced movement: indicating the origins of thought, while offering new spaces for thinking to take place.

What then, might these vignettes tell? The individual stories told here, perhaps, give something of these differentially-attuned moments of experience, and the intertwining of personal memory and public histories on our collective walking-with-light in Brisbane city. As McCormack (2014) asserts, experience is experimented. That is, experience is never pre-given, it is always being made as it happens and is thus always open: always an event of experimentation. Experience is therefore not an "after-the-event event", but the ongoing, qualitative variations of living. In this sense, our workshop was an experiment of experience, an opening to thinking differently - if even just for a moment - and an exercise in attempting to attune to the city-otherwise. Our readings and discussions were moments that oriented us in particular ways to the emergence of attunement, a force of existence that "does not raise itself into awareness", but subtly charts trajectories of movement and thought (Brigstocke and Noorani 2016, 3). Given this, the collaborative element of Cook et al.’s (2016) co-produced conference-session pedagogy is foregrounded, in the way the collectivity of the workshop brought us in concert to create moments of thinking-together along divergent paths. On the other hand, however, insulated and divergent pockets of thought were as much a part of the ecology of experience as that of togetherness, with different bodies, histories and sensibilities participating: we were always together-but-apart, and apart-but-together. 
The material encounter of the walk with city and light, as a contained spacetime, is not an island: what emerges from the reflections is a diverse landscape of experience, one in which the materiality of the city becomes porous with the bodies that meet it. Thus, though cohabiting the same ostensible spacetime, in the actualisation of the event, our eyes, ears, skin and hearts were drawn to different moments, trajectories and potentials of thought and feeling. There are veiled memories of the readings and the discussions, to be sure, but the reflections here show a different kind of memory at work: for us, the affectivity of the city is augmented by the histories that are brought to it. That is, we seek to affirm both the "transformative potential" of encounters to generate "difference and surprise", as well as the pre-existing differences that constitute the conditions of any occasion (Wilson 2017, 464). Simultaneously, our piece offers an alternative response to the charge of hermetically-sealed solipsism in phenomenologically-inspired writing: neither disavowing essential solitude nor despairing at the singularity of an encounter, we instead collect narratives to, together, populate a richer - though still necessarily partial - experiential image of place (see e.g. Wylie 2005, Blacksell 2005, Lorimer 2007).

Rather than being the object of our analysis, we contend that light turned out to be something more like a "weak theory" (Sedgwick 2003, Stewart 2008): a theory that begins as a fault line to initiate thought, but then allows itself to be taken elsewhere, not seeking to paranoidly determine or prescribe what becomes sought. 'Paranoia' is invoked here by the meta-relation of object to knowledge illuminated by queer theorist Sedgwick: "paranoid reading” as a powerful set of “mandatory injunction[s]” $(2003,125)$ for how critical practice should proceed, characterised by habits of detection, demystification and the unveiling of causes (see also Anderson 2018). Building on the space opened up by this critique, Stewart (2008) proposes a weak theory which, instead of grasping for depth in paranoid modes, finds critical potential in staying closely to the surface of a happening, tracking the singularities of encounters to consider how ordinary scenes affect. Our intent is not to undermine the arresting potential of light - light did indeed serve as a force through which we tethered our attachments and enabled an emplaced "attunement to what might rind up or snap into place” (Stewart 2011, 446). Instead, we foreground process: light and writing as attuning forces that introduced elements of difference to the event, giving new potential to an ordinary act of walking the city. As Morris (2011) writes “one’s perception of that which surrounds shifts with the transition to darkness as different kinds of sensory corporeal connections are opened up” (334). The workshop was thus about more than just moving with light, but also what staying with its form enabled: revealing absent and present hauntings in the landscape: intangible presences and intransigent absences that colour perception, despite - or, perhaps, because of their elusive materiality (Edensor 2008; Wylie 2009), revealing different - and always-already 
different - topographies of the city. In this sense, the invitation to write creatively becomes an important moment of dwelling in this act of attunement, a modest technique to draw out that "conjunctive and transitional relation between the process of thinking and the process of experience” (McCormack 2013, 9).

\section{Meandering vignettes}

Taken together, this paper ties into a rethinking across the discipline with the way we, as geographers, write through our earthly encounters. Attunement reveals the excesses of place and the creative translations necessary to turn world into text: but where to go from here? How to tell our stories? Recognising that there is no 'objective' or ideal way of undertaking such a task, researchers engaging the geohumanities ethos have explored the kinds of writing which might emerge out of the slow death of naïve realism, at the intersection of geographic thinking and traditions of creative practice (Madge 2014; Hawkins 2015; Magrane 2015; Springer 2017; Boyd and Edwardes 2019). As argued above, writing matters, in generating new associative possibilities. Whilst the prose collected below reflects the relatively 'finished products' of this process, the proposed task, however, sought more than the production of texts. Collectively, this project also aims to nurture a comfort with engaging as geographers in these creative translations, with the hope of augmenting the possibilities of our social scientific repertoires. Aware that disciplinary shifts involve the acquisition and development of new competencies, our event thus aimed to open further an experimental space for engaging in creative modes of working and writing. Although, as Last (2012) explains, there is a broad agreement that experimentation "should push the limitations of current conventions of representation and knowledge-making" and that " $[\mathrm{t}]$ here is a desire to move away from what is considered 'safe', orderly and established" (708), we foreground not just the limits of the discipline but the capacities of the individual bodies of which it is constituted. Our project, then, is hesitantly pedagogical: not an 'end', but the suggestion of a different pathway (Davies 2010).

In bringing together this piece, we have therefore elected not play the role of arbiter or curator, choosing not to omit, edit or otherwise modify the vignettes that follow, as the judge for the relative success, failure or value of each person's story; hence the perhaps rather unconventional construction of the article. Sidestepping the "canonization of what counts as aesthetically valuable" (Magrane 2015, 92), our vignettes aim instead to together suggest the diversity of engagements that emerged from this particular event, demonstrating the broad spectrum of writing styles that this encompassed. Aided by the solidarity of muddling through this together, we aimed to 
experiment with creatively-oriented performances might do for our geographic practices; picking up the 'geopoetic' invitation, even if some might have felt it fit more awkwardly as a garment. As organisers, the assurance that we were not here to 'judge' the vignettes was part of the open terms upon which we issued the invitation to write: a decision based on the workshop's pedagogical aim. So if, there is a carrier for thinking, a story's “effectiveness is measured not only by its ethics, but also its capacity to move and affect” (Rose 2016, 141; see also Cameron 2012) - that is, if the relative failure or success can be defined by its circumstantial capacity to make a difference - then we leave it up to each reader to determine what these pieces do, or don't do for themselves. We do, however, harbour a minimal hope that the vignettes collectively demonstrate the many ways of feeling and writing through events.

Taken as a whole, our project aims to play with the potentials of writing light at night in Brisbane city. We suggest that our collective experiment offered a moment to inhabit space anew, asking ordinary acts of walking and writing to “dance a little” (Latham 2003, 2000) with light to engender a different sensitivity to the nocturnal cityscape. Our encounters with illumination reveal themselves to be as much about the dark as the light, as experiences of the city at night are modulated by a simultaneous reliance on, and exposure to, the interplay of lighting and darkness. Morris writes that "being immersed in darkness engenders a different sense of self within the landscape ... to that which might be experienced during daylight hours. Distance and proximity become confused and one has the potential to be both visible and invisible” (2011, 335). Indeed, unlike the domestic spaces discussed by Kumar (2015), our encounters were largely in public spaces, in places where the typical sojourner becomes exposed, with limited expectation of controlling, say, the conditions of lighting in a given position. And so, the human body moves, variably yielding to or hastening through the material environments in which the body finds itself. In asking participants to walk, our stories thus emerge largely on the move: attracting interest, repelling attention, demanding, distracting, disorienting, transfixing and transporting, acting as 'agents' in practices of movement (Bille and Sørensen 2007). Taking lead from Stewart's injunction to become "sentient to a world's work" (2011, 445), our stories aim to stay in these descriptive, sensory registers: resisting conclusions, but looking for diversity in accounts of attunement, hinting through engagements with illumination towards a differential attunement with the environment.

Although we have attempted in this introduction to avoid preempting or overdetermining the texts through the invocation of interpretative modes of judgement, there is perhaps one conclusion that we, as organisers, would feel comfortable in asserting. That is, that, like Cook et al. (2016), we 
affirm the productions of working and writing together, as an enabling and "crucial space of peerto-peer pedagogy" (341). We share their view of how, "in small ways, the ... session allowed for collaborative experimentation, a move away from predetermined agendas and learning, a blurring of academic hierarchies and the boundaries between fieldwork, dissemination and pedagogy" (370). Although recognising the oft-mentioned importance of the respect for skill and histories of creative practice (Madge 2014; Hawkins et al. 2015), we also note that the affirmation of creatively-inflected practice's potential for geographic thought emerges alongside a recognition of the difficulty and labour of acquiring such competencies. We are thus allayed by Cresswell's remarks, in his reflections on becoming a poet, that: "[c]reative writing involves reading endlessly and writing with discipline. I hope and believe I am on that road and am willing to risk failure” (2012, 143). We write, therefore, despite the possibility - probability? - of 'failure'.

To conclude, we present the vignettes from the workshop event as something of a virtual walk of its own, speaking to the entangled histories of the event, our bodies, and Brisbane city. As in our method of tracking the transformation of movement and thought into prose, we give the event over once more, this time to the reader. Arriving in Brisbane with Ben Iaquinto, we hazardously traverse bridges with Ainsley Hughes, chase cars with David Kelly, travel through time with Cambpell McKay ... we then snake over streets, slide along rivers, duck into laneways, all the while accompanied by new friends, old ghosts and emerging accomplices. Collectively, we meander through the illuminated nightscapes of that warm winter's day in July, with the hope that something here might move you too. 

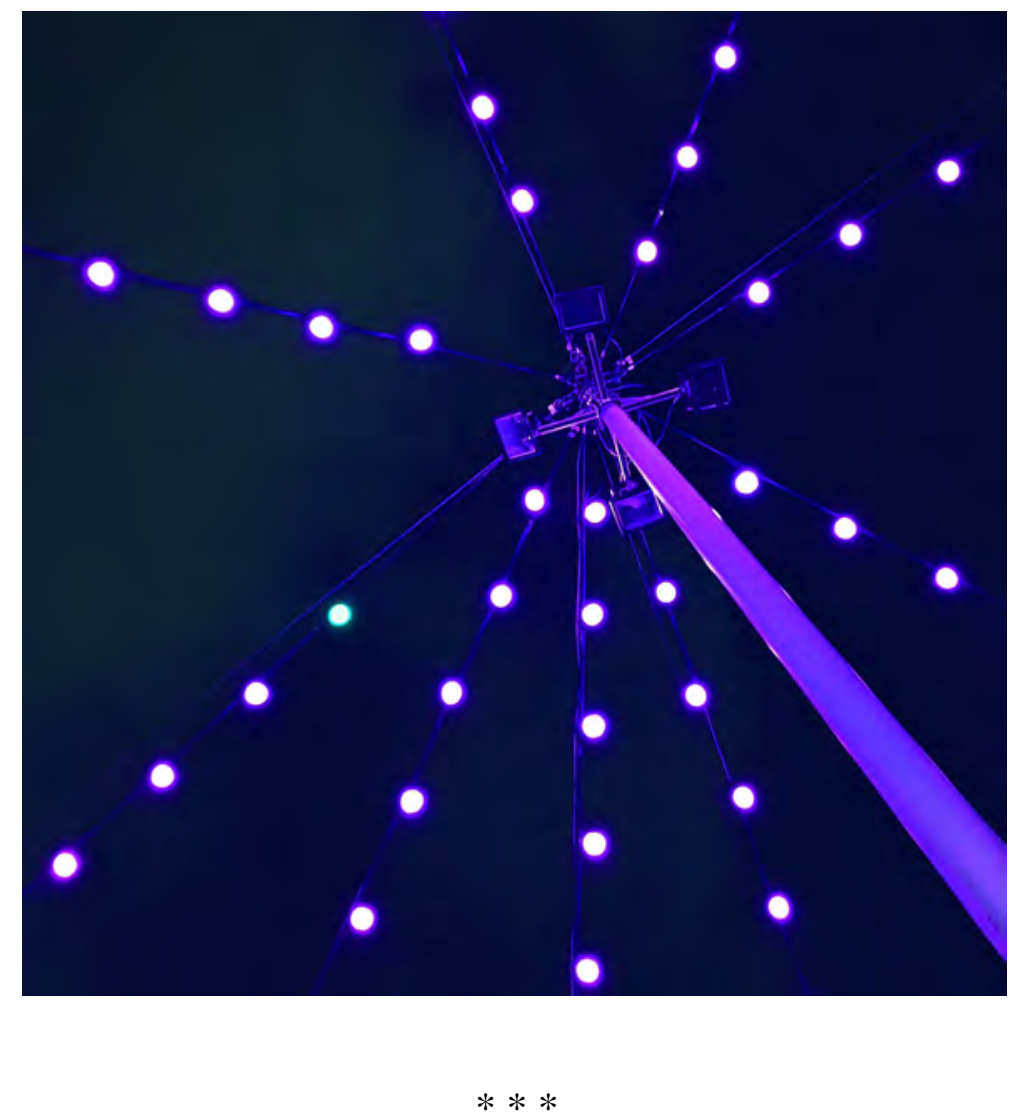

\section{WELCOME TO BRISNEYLAND}

Benjamin Lucca Iaquinto, The University of Hong Kong

It took my eyes a while to adjust. Everything was incongruous, thrown together, messed up. Each light seemed to be lit for a different purpose.

There was a bridge that glowed dark red, a string of purple lights in the sky, a grassy hillside blazing with light (nobody was there), distant planes flickering like fireflies, cyclists blinking white and red (safety first), corporate logos glowing atop skyscrapers, Captain America, Tomorrow When The War Began, cigarettes, billboards, phones, and above it all - tiny stars shining through Deep Time.

Squinting at night was not unusual. 
There were lights that repelled me and lights that drew me in. So conspicuous was that hillside, standing under that blazing light would have been unbearable. You would need sunglasses. A 'Keep Off The Grass' sign could have worked, but not as well as making the grass brighter than daylight.

Near the Art Gallery were strings of purple lights above an empty courtyard. The lights were so festive it didn't matter that nobody was there. Among all of that purple was the occasional differently coloured bulb. Those really stood out. Sometimes red, sometimes yellow, blue.

Around the Queensland Art Gallery and Museum, the landscaping was lit up. Rows of shrubs planted along handrails were illuminated. Plants were encased in glass cabinets that had light bulbs glowing above them. At first glance the lights seemed to be lit to make the plants conspicuous. But the bulbs shone too brightly, their wattage way higher than what was needed to notice the plants.

The city wants us to move in certain ways, to go to certain places, and to avoid others. The lights funnelled us in certain directions: channelling our movements, shaping our mobilities, directing our gaze. Lights can be a welcome or a warning. We avoided bright lights and darkness. We sought out places with favourable illumination.

\section{SUSPENDED}

\section{Ainsley Hughes, The University of Newcastle, Australia}

The Brisbane River twists through the city cutting the surrounding landscape into bordered pieces. Moving in this city has made me feel like I'm playing a giant game of snakes and ladders. I spend time climbing my way by foot through one of these city pieces, only to slide down across the river into a new one via one of the many pedestrian bridges.

I am walking across the Kurilpa Bridge heading towards the meeting spot at South Brisbane train station for our night time conference session. I am starting to run late and chose this pedestrian bridge on a whim. I would like to say it was intuition or planning that snaked me down this path, but like so much of my wayfinding, blind hope and the pressure of a ticking watch dominated my decision-making. 
As I walk across the bridge I begin to scan the horizon for landmarks which will help me find my way once on the other side. I look to my left and despite running late, I am struck by the beauty of the city against the setting daylight. I pause. I take a moment to appreciate the colours of the sunset: blues, oranges, pinks. The subtle light reflects the shapes of buildings on the water, adding grey and navy to the palette. I am suspended for a few seconds on the bridge, hovering above the river, floating somewhere in-between the many puzzle pieces of the city. I take a photo and send it to a friend; a digital postcard loaded with all the colours and affections I feel in this twilight moment.

Some hours later as our session continues and the sun has long set, I find myself this time snaking across the city via the Goodwill Bridge. There are large lights, the size of dinner plates, on either side of the walkway illuminating the path for pedestrians and cyclists. This time I'm not pressured by my watch and the lights carry me, much like an aeroplane being guided to its final destination by the lights of a runway. I glide without thinking.

But in a moment things shift again. I step to the left of the bridge to make room for a cyclist moving past me. This forces me to walk directly over the path of the uplights. I look down at my feet, and the light blazes straight up into my face, making me feel momentarily dazed. For a few seconds I am suspended in space, suspended on a bridge again, hovering above the river and feeling somewhere in-between. But this time it's uncomfortable: the city around me hidden from view, eclipsed by the intense and artificial light that has filled my head. I carry this feeling in my body for a few more steps, as the light continues to speckle before my eyes. I'm not gliding anymore, but stumbling. I take a photo, but this time the result betrays the moment held in dizzy head - just an empty 2D frame, with an obscuring white shape, and perhaps the edge of my coat.

\section{LIGHTWALK: BRISBANE 10-11 JULY, 2017}

Tim Edensor, The University of Melbourne \& Manchester Metropolitan University

\section{Foregrounding architecture}

Light focuses attention on the architectural qualities of the Treasury Casino and City Hall. Iconic heritage structures, it is these sorts of buildings that are typically highlighted with illumination. 
Their architectural merit is certainly enhanced, light making certain features stand out, but other buildings are shroued in gloom. How might the city be configured differently through light?

\section{Light and water}

In Brisbane, there is a munificent interaction between light and water, the dynamism of each element forcefully combining. Water gushes, ripples, flows, spatters, drips and trickles and these processes are augmented by the ways in which illumination immanently sparkles, reflects, colours and shines. Illuminated fountains, pools, waterfalls and streams have long been an integral constituent in the design of urban public spaces, especially in renowned squares and parks, calming, perhaps mesmerising us, with the combined effects of flickering light, fluid movement and layered sound. In addition to these designed water features, reflected light in the Brisbane River enhances the nocturnal appearance of the city - its bridges, towers and functional lighting fixtures.

\section{Invitations to perform}

Light guides people along preferred pathways, practically organizes pedestrian movement in spaces that would otherwise lack distinguishable routes and transforms the aesthetic appearance of the paths themselves. But illumination also solicits people to perform in more expressive ways. The Brisbane sign, illuminated at night, is a sturdy feature that allows visitors to climb on top of the letters, or weave in and out of the spaces between them. And a wall of water, composed of glass bricks, illuminated by LEDs and continuously changing colour serves as a backdrop for photography. As I passed it, it was a venue for two couple to enact a series of poses that appeared as silhouette against the vibrant, illuminated hues and the cascading water. These hot spots of nocturnal interactivity contrast with their sedate ambience during daylight hours.

\section{Delineating horizontal and vertical elements}

The lightscape produces a pared down city in which its rectilinear qualities are foregrounded without being obfuscated by the visual clutter that accompanies them by daylight. It brings out the essential geometry of the city, the horizontality of steps, bridges and building feature are accentuated, along withvertical features, tower blocks and large cranes, their delicate structure is delineated by illumination so that they assume a more abiding presence by night. 


\section{Nostalgia}

Under the bridge on the South Bank on Melbourne Street, there are two adjacent installations. One is a simple band of illumination that takes the form of a cinema or dance hall awning, with letters that read 'TROCADERO DANSANT', conjuring up a 20th century space that transports those in search of night-time entertainment to realms of romance, fantasy and celluloid escape. The other compounds this nostalgic charge with an illuminated mosaic that celebrates the dance bands, audiences, dancers and celebrities that congregated in such places. Light provokes a nostalgic sense of times past, an intimation also present in the neon sign that heralds the Oasis Juice Bar on the Queen Street Mall.

\section{The shapely forms of trees}

Though some may cavil at the application of human technology to augment a natural feature, light can provide an intensified appreciation of the form of the tree, its distinctiveness, in ways that simply cannot be accomplished by day. The arboreal architecture, positioned against a dark backdrop, renews our acquaintance with these co-inhabitants of the city.

\section{ABUNDANCE ON ATTUNEMENT}

\section{David Kelly, Deakin University}

Arrested. Yet the red streaks still duck and weave, threading the city's pedways and watercourses. My body is drawn. Distracted by the trajectories of light ushering in other far-off spaces. Where do these cars go, I speculate? These taillights signal the manifest absence of somewhere else. The presence of all possibility in the banking of cars and buses, packed with ever more trajectories and arrivals. My attentions wane with the complexity of abundant past-presents and present-futures. Don’t think it, ‘just move’ I tell myself.

Just moving, walking with the bridge, we continually negotiate our engagement. The water below speaks back and I imagine its story - its negotiations upstream, downstream. Don't mention 'the floods', as if the river remembers. Don't mention 'the drought'. 
The red light dancing with the river makes me think of the cars all banked up along that bridge. But as I pause at the grated fence, I am reminded to forget the cars, despite headlight enchantments. The bridge falls into the city, amidst towering concrete and glass profusions. Pushed down and through into a mass of signage and lights I and pulled upward to water fountain perched atop the humming streets.

Lit-up, water is given a ceremonial welcoming to the city, as if the drowning light belies the worst prolonged droughts on record. Scarcity and scale - denied with the flowing glittery wetness. Manifest absences, again, lurk in the dark gaps between the turbulence of the flow. Illumination is opiate for the scorched earths that deliver such a moistness to the urban.

Light in the city of Brisbane gives a presentness to an atmosphere of abundance - an abundance of water and light, of resources that assemble outside, somewhere in the hinterland, and parades through the city, lit-up in ceremony. The paradox of awe and banality in the streaming of water is nullified in the framing of spectacles by light. Light draws attentions but offers up moments and trajectories of attunement. Attunement to the ecologies of water and the infrastructures that channel vitalities, bringing them to our attention and offering up points of insurgency into the narratives of their being, their political lives that are past-present and present-future. Does light pacify the life of water in a thirsty city until the moment where it puts the lights out? 


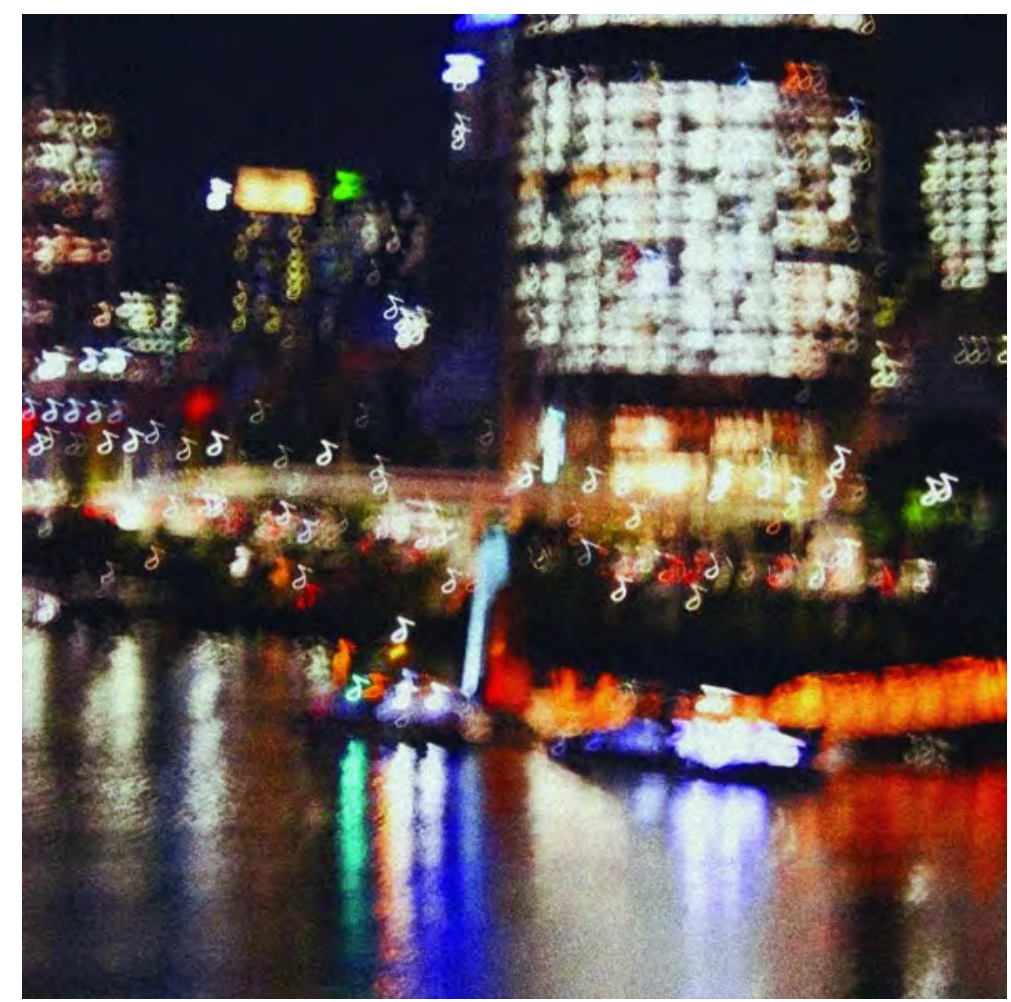

\section{$* * *$ \\ SUBMERGED IN THE SPECTRALITY OF BRISBANE'S BOARDWALKS}

Cambpell McKay, The University of New South Wales

I had never before visited Brisbane when the floods hit in 2010, though the images featured in media reports enabled its consumption from a distance. I distinctly recall a particular empathetic relationship forged through the photographs of a city submerged by water - it triggered something local, a commonality for Australian city-dwellers alike. Diluted streetscapes provided a visual spectacle, in turn forcing us to question the efficacy of such a tragedy through our own roads and avenues. However, what are noticeably absent in my memory are the nocturnal geographies of this traumatic event.

Each of these stones, each of these wooden planks, exploits the illuminated city to enliven a domestic moment hidden from those who watched from afar. As I traversed the boardwalk I watch as water pierces upwards from the cracks, covering my ankles, soaking my pants - a childlike fear of the night intensifying these spectral imaginaries. There is loneliness. There is the abyss. Guilt 
washes over me in receiving these new pasts that my own ambivalence had protected me from. Fresh empathetic relations are forged between my body and the city. I care for this moment, but the moment has past.

Yet Brisbane also gives. Each footstep in the present performs a protest against these same emotions - these boardwalks now raised above the river provide a safe space to challenge the hegemony of disaster. The city's refusal to be sunk by the floods is intoxicating, and it flows unabated from the nightly movements on these boardwalks. While the spectacular illuminations of the nearby cityscape enable this journey, it is on these mundane paths that I attune to the Brisbane of the present. Walking these ghostly landscapes thus performs a symbiosis with the city, as it is these new registers of knowing that I carry through its streets.

\title{
BURSTS OF CITYLIGHT: JETS, POOLS AND FLARES ON THE BRISBANE WATERFRONT
}

\author{
Michele Lobo, Deakin University
}

How can one learn how to feel light and contribute to making the city a more diverse and inclusive space? As a migrant woman of Indian heritage, I inhabit the shadows of Australian suburbia - the bright lights of the inner city that lure, dazzle or blind always seem so distant. How, then is it possible to learn how to feel city lights in a strange place away from home? This workshop helped me feel the movement and intensity of light as I walked along the Brisbane Waterfront and sailed along the Brisbane River.

\section{WALKING THE STREETS}

Moving slowly along the streets, paths and promenades in the Waterfront precinct, I feel pools of light in the parklands soothing, watery jets of the Brisbane Wheel delightful but the glare of nightlife blinding. 


\section{SAILING}

For me meandering in the city is more than walking - it resonates with sailing or gently rocking along the Brisbane river at sunset. This movement provides a different feeling of light - neon flares of the Kurilpa Bridge (named after Indigenous ancestors) are inviting and the Brisbane skyline with its illuminated towers ethereal. It seems there are differences in how I feel light while walking the streets or sailing down the river.

A multiplicity of sounds, moving shadows and the feeling of mobility/immobility open my body to the affective experience of inhabiting atmospheres of a tropical coastal city. While visual technologies enable me to illuminate multisensory experiences, there is always something about light, darkness and movement that exceeds capture. I inhabit the shadows of suburbia with its dark neighbourhood streets and creeks but also warehouses, factories, construction sites, carparks, 'dangerous' railway stations and fast food restaurants. Perhaps this maybe why I turned away from feeling the light and patterned shadows in ground level car parks and construction sites inhabited by invisible workers as they revitalise the Brisbane Waterfront.

In these peripatetic ramblings, an affective pedagogy enabled by smart phones and apps as allies opens my body to human as well as more-than-human worlds, Indigenous songlines and diverse ways of life. Such a pedagogy is crucial in making cities in white majority societies vibrant, creative, liveable but also diverse, inclusive and nourishing. An affective pedagogy can be radical if it brings forth new habits, new perceptions, and attunes us to new ways of relating to the world (Rose-Antoinette, 2016, Stewart 2011). Rose-Antoinette (2016) argues that movement enables knowing to happen because it occurs through discovery; it is the 'wilderness of knowledge' and the risks involved that give such a radical pedagogy flesh (119).

\section{FOLLOWING THE LIGHT LURE}

\section{Melissa Kennedy, La Trobe University}

I found my way to Fish Lane by accident after becoming separated from the group. Its neon sign stood out like beacon, steering me off course from Melbourne Street and down a side alley. 
It takes a second for my eyes to adjust to the darkness. Although it appears that I am in a dimly lit car park, I notice that there are some people clustered around the back of a shipping container. Feeling unsure of whether I am in a public or private place is unsettling, but I am drawn to the warm light beyond. Cutting through a seating area I end up on Fish Lane itself. The string of light bulbs overhead dazzle as they zigzag from building to building.

It is now clear that these lights are pronouncing Fish Lane as a dining precinct, a consumption space and assertion of its place in Brisbane's nighttime economy. Patrons for a busy Italian Pizzeria overflow onto the path as they queue for tables. The orange flicker of gas-heaters contributes to the convivial atmosphere as flustered waiters attend to outdoor tables. The train rumbles overhead, bringing sound and light together in a fleeting moment. I am momentarily transported from Italy to Tokyo’s Yakitori Alley. A brick building repurposed as a 'Beer Café' is illuminated by the gaudy flashings of pinball machines. Walking past, a young guy announces to his group 'Let's get ribs!' as they stride quickly towards an American-style diner.

The string of bulbs extends into the next block and then another. I advance further, crossing a busy road and surrendering to the pull of the anglerfish-esque lights in this metaphorical midnight zone. I do not feel like I am being lured into danger, despite the peripheral darkness that blurs the edges, masking quotidian services like auto-repairs. Nature is muted here at night, with plants and trees faintly illuminated by the overspill of apartment lighting. The darkness conceals other things too, like the expansive mural depicting a charity for war victims. Yet in other places, public art is more pronounced. A large banner of a woman emerging from steam pipes (a nod to Fish Lane’s industrial past) is accentuated by the light bulbs, resemblant of a Hollywood mirror.

Following the light in Fish Lane is an affective process, where the strange is made familiar through the replication of a global aesthetic. It is in the pockets of darkness that deeper glimpses of nature and place appear. 


\title{
WANDERING AND ILLUMINATION
}

\author{
Peta Wolifson, The University of New South Wales \\ Charishma Ratnam, The University of New South Wales \\ Caitlin Buckle, The University of New South Wales
}

On our departure from South Brisbane Station we immediately reflected on the power of lighting to guide our night-time course around the city. We were guided towards the Brisbane River, where the bridge, lit in red light, reflected across the water. A local amongst our group remarked on the affective contrast from this pleasant night-time illumination with the river's unpleasant colour during the day.

The coulourfully lit Brisbane sign - a mandatory Kodak moment - announces Brisbane as the world city it desires to be. Along the same pathway, the almost blindingly bright white light of the wheel of Brisbane - corporatized with the Channel 7 logo - illuminated a fairly empty space along the riverside. Instead of returning along Melbourne Street, we were drawn like moths to a flame into a pedestrian tunnel where fluorescent white lights highlighted the emptiness of the space. We crossed at traffic lights, our pace quickened by the technocratic measure of the lit countdown timer. A rail underpass featured the light pieces - 'Trocadero Dansant' and 'Blue Moon' - that added quirk and interest.

In Melbourne Street, we were struck by over-illumination affecting a somewhat frantic atmosphere that highlighted the busyness of the street. Street lights and well-lit businesses were bordered by trees and hedges lit up by ground lights and lanterns featured in trees . The contrast as we turned off into the more residential Manning Street was striking, with its sparse street lights and the change from white to yellow light. Only lights from windows of individual apartments in the blocks above signalled where residents were home. A lone woman sat on a step at street level, her face glowing in the darkness from her laptop screen. At the end of the street we arrived at a wide road in a dark industrial area. Our eyes were drawn to the blue-light illuminated toll way. Without a designated crossing we carefully crossed the road, with only headlights to signify oncoming traffic.

The Kurilpa Bridge was heavily lit with white light from above and below. It potentially could have provided a pleasant, atmospheric vantage point to view the Brisbane river and skyline, 
however the excessive lighting instead drew our eyes inward to the grey, uninviting, concrete brutality of the bridge itself.

Leaving the bridge, a bus stop where two elderly people sat conversing appeared as a sanctuary of light amid the surrounding darkness. We made our way along Roma Street to King George Square, where the striking architecture of the City Hall was illuminated with pink-red light, less effective due to the empty square in front of it featuring a large television, watched by apparently no one.

On the other side of the square, the shopfronts of the pedestrian Queen Street Mall were illuminated with familiar businesses - large corporations inhabiting the street-scale in the Brisbane CBD. The brighter the light, the cheaper and 'faster' the product sold - beckoning to everyone - contrasted with the warm but dim lights of the exclusive high-end stores. Our attentiveness to light had a dizzying affect and the impression of illumination was everywhere.

Finally, to a drink in the pub, the dimness something of a relief. 


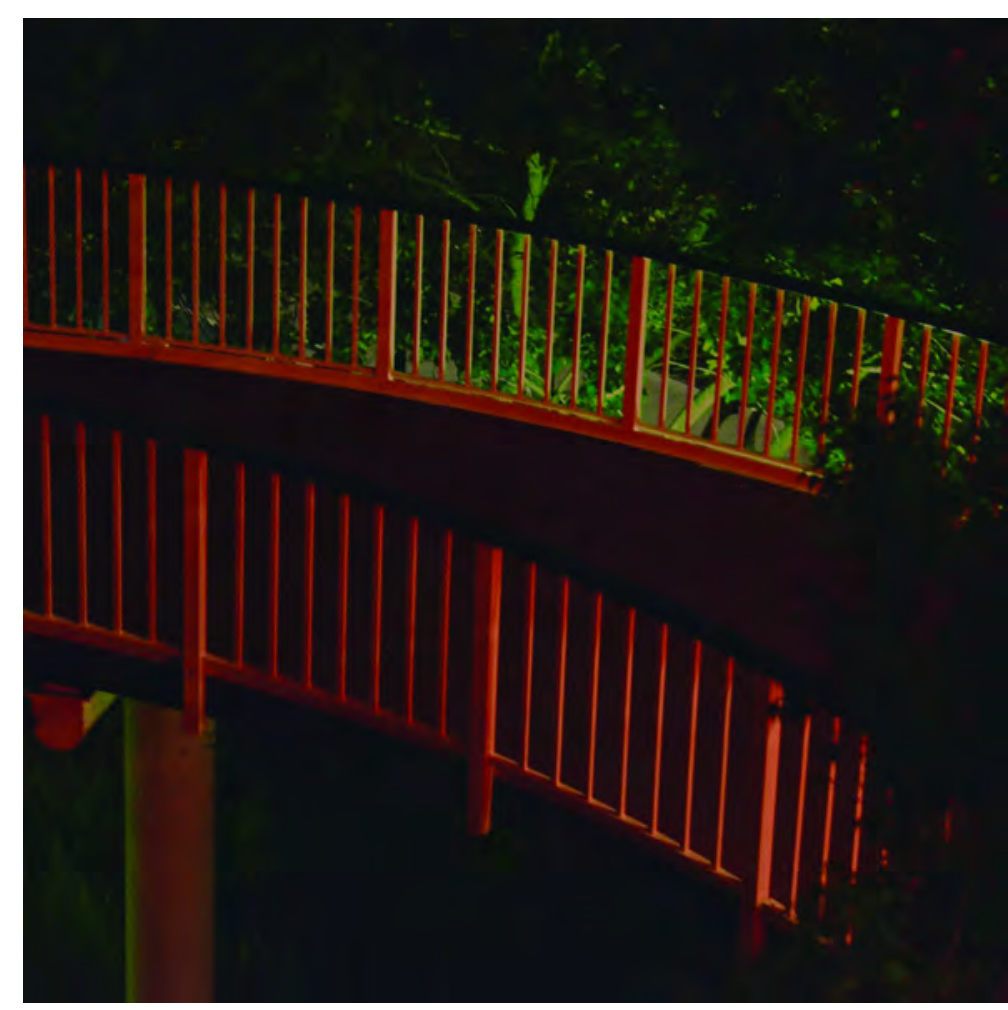

THE PELICAN

Louise Bérénice Dorignon, The University of Melbourne \& Université Lumière Lyon 2

She has just returned from France. The trip was rough, her heart was broken. She was reluctant to return to Australia. By the time she finds herself in the Brisbane winter, she feels a little shaken. She meets with the group of researchers at the gallery, many of whom she doesn't know. She feels homesick and isolated, but she accepts this exercise as a practice for her own healing. Along the way she shares her sorrow, and what it is like to grieve in an unfamiliar place. She finds unexpected comfort in this strange and nocturnal walk.

They commence their hunt for lights entre chien et loup, between dog and wolf. Fervently, they look everywhere to catch a ray of light, a vivid colour or an unusual silhouette. Their photographic attempt to collect the glare of the city happens mainly on this bank of the river. Here, artificial lighting has been carefully staged to enhance the theatrical aspect of the art precinct and create a 
serene atmosphere after dark. She switches her camera settings to black and white and softly enters the set.

A flock of five bronze pelicans are nearby watching her, perched on blocks of bright cement and surrounded by water. The fountains are lit from underneath with golden spotlights. She captures the pelicans under the modernist contours of the gallery's exterior walls. She will find out later that the birds have been modelled by Leonard and Kathleen Shillam, poultry farmers and sculptors who set up a foundry studio in Brisbane in the 1980s. She is struck by the restfulness of the artwork. The birds are made cinematic by the simultaneous undulations of the water and of the coloured lights.

She walks towards the natural history museum. In the grand arcade, she gets lost in the inspection of the minuscule. She notices the luminous letters directing to the entrance of the museum, a black "M" lit from the inside and reminiscent of Fritz Lang with its menacing bearing. Picturesque images of solitary gallery rooms after hours come to her mind as she recalls scenes from the muchloved Hitchcock movies of her childhood: the eerie and troubling fascination for the portrait of an ancestor in Vertigo, the anxious chase through an East-Berlin museum in Torn Curtain.

The presence of two huge whales above her head brings her back to Brisbane and reassures her. Their wide and white abdomen guide the visitors through the covered walkway. They are suspended in the ceiling as if they were whirling soundlessly in the ocean. The whales accompany them towards an outside garden where they sit for a little moment. She stares at the parterre while they converse. She is mesmerized by the green and purple of the leaves in the obscurity. Soon they will cross the bridge and walk away from the museum's soothing melancholy.

A few days later she revisits the gallery, alone this time. She chooses a bench on the other side of the fountain. She closes her eyes to feel their presence. It is the morning and they are all here, the black-eyed and iridescent pelicans on their concrete pedestals. 


\section{LA CIUDAD}

\section{Laura Rodriguez Castro, Griffith University}

I have been familiar with Brisbane city for several years, but I had never made a conscious attempt to attune to the city's lightscape. I was pleasantly surprised to see how the light influenced my experience of the city. I have always liked West End's atmosphere, and that is where we headed first on our walk. Melbourne Street in West End is decorated with lanterns hanging out of trees that add 'Asian' elements to an increasingly multicultural and gentrified suburb. The lanterns, the dark alleyways and neon restaurant signs create an intimate atmosphere for a night out.

Then, as we headed towards the city, we went to the famous landmark of the Brisbane Wheel where the intensity of white light is met with the ABC News headlines streamed on a digital screen. This highly illuminated site attracts tourists. As we sat down to observe the wheel and its surroundings, pedestrians with suits and business clothes pass by without paying much attention to the highly illuminated landmark. Then another thought came to me and I wondered how the intensity of the wheel's illumination might impact the wildlife around South Bank?

After the wheel we headed to my favourite part of the walk, which overlooks the city over Brisbane River in South Bank. The city reflecting on the water, the different coloured lights (mostly red), combined with the soundscape of a pedestrian only path gave me a sense of tranquillity. I wondered: I have seen this view with many other coloured lights, how are the lighting decisions made for each night?

Finally, as we walked along the bridge towards Brisbane city my experience was disrupted by the changing soundscape that transformed from a tranquil pedestrian path to a busy street with heavy traffic. As we walked over the bridge, you can see the busy streets with cars' strong and bright headlights, horns beeping and loud engines. This was particularly interesting, as the lighting on the narrow bridge pathway is quite plain and added to the traffic noise it might lead pedestrians to walk faster along the bridge. I also noted the disruption and change in my experience of the space due to the changing soundscape on several moments during our walk when we encountered heavy traffic on the streets. 
Noticing Brisbane's range of light intensities and absences made me reflect on how this city is purposefully designed in many particular ways to give a pleasant experience of the space. The intimate lantern lights, the neon signs, the illuminated trees, the horizontal lighting that connects the city to South Bank, and the difference in illumination of the buildings that make up the city cocreate a space that is also constructed by the soundscape, the people and the nonhuman. I wondered whether my home city Bogotá, had been designed with such consciousness. I miss the chaos.

\section{FOLLOWING}

\section{Elizabeth Adamczyk, The University of Newcastle, Australia}

As the sun is setting in Brisbane I meet the group to discover what the city's illuminations might communicate to us. Three of us set out together. Pulled by the dazzling lights of the Riverside walk, we move. We are guided through the whimsy created by what seems to be an ironically carefully considered interplay of structural framing, purple flora, and LED lights. Every so often, transitory spaces emerge: an emergency phone mounted on a concrete post, a snippet of a skyline rising above the canopy, an up-lit tree emerging from the bushes. We stop for a moment and discuss whether we continue through the spectacle or alternatively go off-course and into the deviant space of the dark. Whether we subvert or follow, I can't help but feel that the coercive power of illumination is carefully directing where we move and what we afford our attention to.

We come to a bridge. At first, we are urged forward by the uniform curvature of fluorescent light funnelling people to the other side of the city. Skyward, corporate logos bathe the skyline is shades of fluro, storying a neon narrative that infuses the cityscape with a colourful hue. Overhead, commercial and educational institutions carve out their carefully manicured corporate meaning]. Such an intentional activation of this cityscape through corporatised illuminations acts as a kind of message board to communicate. Reminded of the lighting policies that work to create a carefully crafted night-time image in other cities such as Sydney, I am provoked to wonder whose hands govern over the impulses that colonise this city’s darkness. 


\section{Interjecting}

As we reach some point along the bridge, rather than continuing forward, far away light interrupts our journey, beckoning us to stop for a moment. We look up to where the lights illuminate the skyline in carefully manicured ways. Below, we look down to the Brisbane River where waves ripple in the water. Instead of a pure reflection of the colours we see above, made pronounced through the water is a bright blue image. We are confused. Where is this bright blue originating from? And where has the bright green disappeared to? We can't quickly match the images to their source above. The waves, rippling in the dark haze of night muddy the dominance in the illuminating storyline, shapeshifting what we perceive from above where the deep blue dominates. Watery reflections tell an alternative story, confusing what illuminations infuse the city and in that moment the water interjects in representations of knowing.

\section{SUNSET-DUSK-CARPARK}

\section{Kaya Barry, Griffith University}

The light changed rapidly as we walked into the entrance of the Grey Street carpark. The tones of the shadows deepened, the outside light faded, and then was quickly replaced by the spill of fluorescent lights, bouncing off the painted concrete pillars. We stepped into the carpark just after sunset. Perhaps dusk is more accurate. The ambience feels familiar, but in a way that is not necessarily location specific. I try to think back to what this sensation reminds me of, thinking of other cityscapes beyond Brisbane that I've visited. The memories are recalled as a mixture of atmospheric light — usually dusk — and the motion of my body moving as I walk. There are small glimpses of architectures, materials, and cool temperatures, but mostly I feel the changing light, from daylight to dusk, and then to artificial lighting, that congeals as memory. Standing in the carpark here, in a city that I know so well, draws together these sensations of previous experiences of dusk. Perhaps it has something to do with the circadian rhythm, that these transitional spaces draw out and intensify the synchronisation from daylight to dusk to architectural light?

There were three in our group who wandered off to explore Brisbane's light and atmospheres. We didn't get far, the carpark entrance lured us in. Pausing to adjust our eyes and other senses, I told them how this car park thoroughfare was one of my favourite spaces in the South Brisbane area. 
They asked why, and I couldn't put an immediate reason together. Was it the excess of concrete that envelops as you walk through? Was it because in summer this is one of the only completely shaded (and therefore cool) walkways on this side of the river? Or is it the rumbles of the trains and busway above, and the heady mixture of the starchy concrete surfaces and the exhaust fumes in the carpark? Feeling the vibrations of the peak-hour trains overhead, and allowing my eyes to adjust to the contrasts between the dim and the glare, I was jolted back into focus by sharp headlights of a car pulling out. Pedestrians and cyclists moved past us, but trying to follow each one quickly became disorienting as the people kept flowing through. I'm less attentive to the shadows being cast by the movements, and more interested in feeling the transition from dusk to dark to the carpark lights. I look back outside and the dusk is gone, replaced with more street lighting and the glow of car brake lights. 

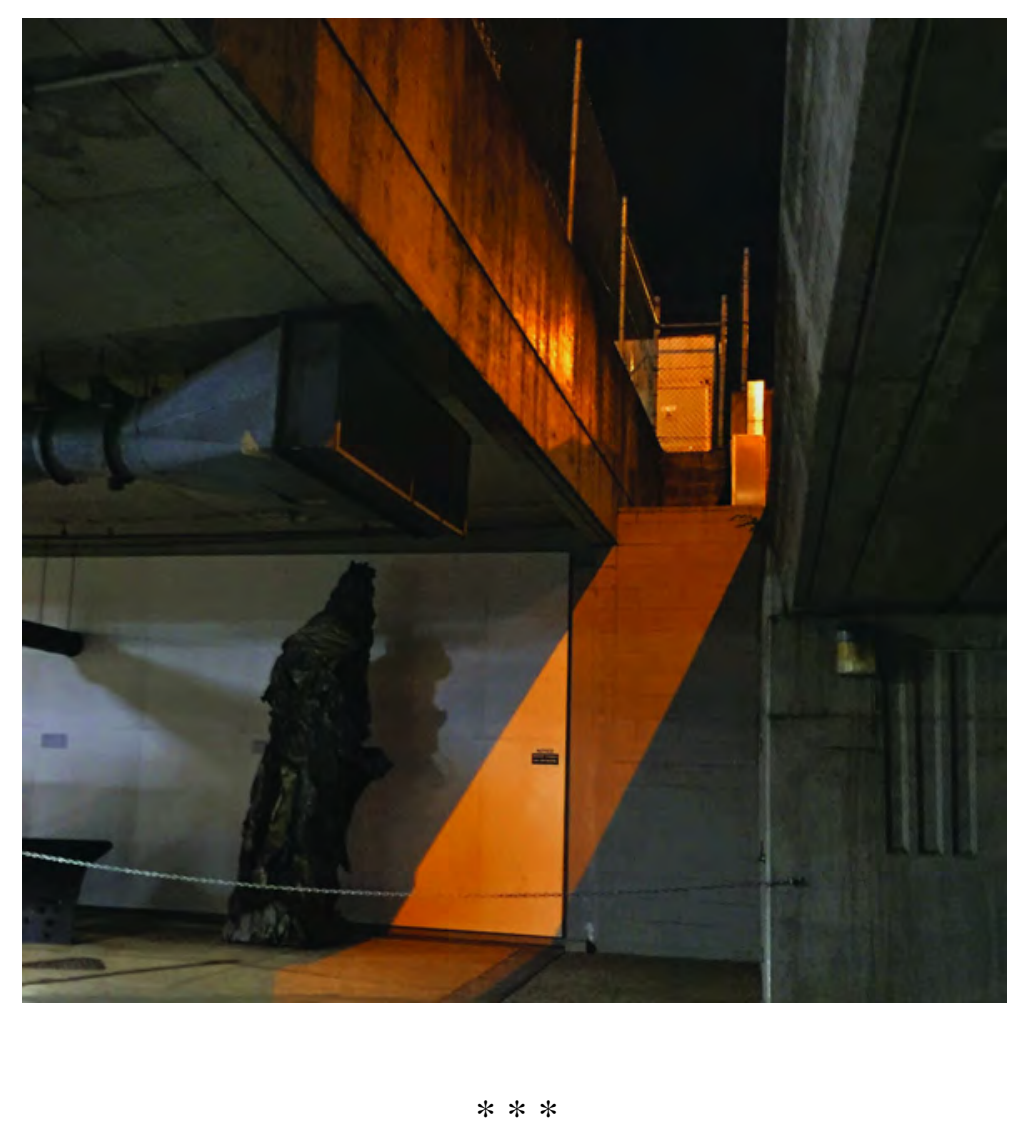

\section{EMBERS}

David Bissell, The University of Melbourne

Thousands of tiny gold embers fall from the Banyan tree. It's an arboreal supernova; the aftereffects of an expired event. Its life has run its course, used up its reserves, and it has died in the most spectacular manner.

But this is a freeze-framed supernova. Under the Banyan tree, the embers are arrested; caught in the act before they will touch down. Before they will ignite the leaf litter below; before they will set fire to you and me; before they will set the city ablaze.

I have a recurring dream where a missile lit from within, like a giant blue-white fluorescent tube, torpedoes towards me at lightning speed through a black sky. Before reaching me, it explodes. In silence, the tube fragments into thousands of tiny gold embers. I watch the scene helpless, overpowered by its speed, wishing it to stop. 
Under the Banyan tree, it has stopped. The embers are suspended. And as they are stilled, they make a shelter beneath to inhabit, like a cave. I look up and wonder how to dwell in the aftereffects of expired events.

But this cave is deceptive. I see some embers moving, barely perceptibly. They must still be falling, but falling so slowly that my perception of time is drawn out. Under the Banyan tree, every splitsecond must last hundreds of years.

In this stilled time, cause and effect are stretched so far apart that nothing is comprehensible. But still, thoughts race at lightning speed through the silence that has become overwhelming. Bluewhite fluorescent thoughts that torpedo from within.

We seek shelter from expired events, desperately. But what if our shelters turn out to be those expired events? In time stilled, they are lived endlessly. Thousands of tiny gold embers fall from the Banyan tree.

\section{A SHARD, SHIMMERING}

\section{Vickie Zhang, The University of Melbourne}

As I herd myself home via Brisbane airport, it suddenly hits me that I'm exhausted. Sitting under fluorescent lights, I wilt, as the energetic intensity of the past days drains from my body. Unstirred by my pale sushi dinner in the garish food court, I long for the fleeting hour of flight-time stasis.

When I finally drift aboard the brightly-lit evening flight, I am carried more by habit than volition. Stopping at my aisle, I am unimpressed to find a small child merrily ensconced in my carefullychosen window seat. Clad in a plastic yellow hard-hat, the little boy rummages excitedly through a Bob the Builder backpack, his mother and a nearby flight attendant gazing on with tender eyes. Noticing my pause, the smiling attendant swiftly gestures to the aisle seat, asking whether I might instead take the child's assigned place. With the pure indifference of exhaustion, I decline. The attendant's face fills with horror; the mother flusters, and flutters to gather up her child. Satisfied, I relax into my seat and rest my weary head against the window. Outside, the twilight fades to night. 
I awake suddenly, still bleary-eyed. The cabin has been dimmed, and only a faint haze remains, transitioning slowly between dusty pinks and muted blues. Half an hour has passed, and the food cart sits a few rows ahead. Paid by my university, it is the first time in years I do not find myself on a budget airline. Drifting in and out of waking life, I will myself to inhabit the murky space between asleep and awake for a little longer. Finally, the attendant hands over a small bag and serviette. Pretzels and almonds. Damn. I fall straight back to sleep.

I'm shocked to sentience again by the crackling announcement of our descent. Eyes pressed stubbornly shut, my darkened sight heightens the other senses, amplifying the jumpy knot in my stomach as it tracks alongside the plane’s falling arc. Draped awkwardly over the narrow seat, my neck aches with the memory of its contortion.

Brian Massumi (2002) reminds us that "perception is never only impression. It is already composite. Studding each impression are shards of intentions and conscious memories ... shimmers of reflection and language” (75). Here, my perception has become furnished with a new glimmer: a reflexive sensitivity to light and its capacities. Writing this now, days after the event, I'm not yet sure what this attunement might do. Will it grow into a brilliant, irrepressible sparkle? Or will it slowly fade from memory, scattered for a future nostalgia? I do not know. But I know that, now that I see it, I cannot unsee light. The event leaves its residue: a perceptible shard, a palpable shimmer.

\section{NOTES}

1 Thank you to Candice Boyd for drawing our attention to this quote.

\section{ACKNOWLEDGEMENTS}

The organisers would like to thank Tim Edensor for presenting the workshop and Michele Lobo for her tireless support in organising the workshop and paper project. We'd also like to thank Tim, Michele, David Bissell, Clare Southerton and the Geography \& Environmental Studies reading group at the University of Newcastle, Australia, for their feedback at various stages of drafting, and Ben Iaquinto, whose gentle cross-continental rebukes in particular kept enthusiasm for the project alive. We are grateful for the thought-provoking comments of the three anonymous 
reviewers, whose words will resonate even after this piece is done and dusted, and the generous editorial guidance of Deborah Dixon and Jennifer Cassidento. Finally, we're thankful to all those who participated in the workshop on the day, including those who did not submit writing to this paper.

\section{REFERENCES}

Anderson, B. 2018. Cultural geography II: The force of representations. Progress in Human Geography OnlineFirst:1-13. DOI: 10.1177/0309132518761431

Bille, M. and T. Sørensen. 2007. An anthropology of luminosity: the agency of light, Journal of Material Culture 12 (3):263-284.

Bissell, D. 2010. Passenger mobilities: affective atmospheres and the sociality of public transport. Environment and Planning D: Society and Space 28 (2):270-289.

Blacksell, M. 2005. A walk on the South West Coast Path: a view from the Other side. Transactions of the Institute of British Geographers 30 (4):518-520.

Boyd, C. P. and Edwardes, C. (Eds.) 2019. Non-Representational Theory and the Creative Arts. London, UK: Palgrave Macmillan.

Brigstocke, J., and T. Noorani. 2016. Posthuman Attunements: Aesthetics, Authority and the Arts of Creative Listening. GeoHumanities 2 (1):1-7.

Cameron, E. 2012. New geographies of story and storytelling. Progress in Human Geography 36 (5):573-592.

Cook, S., A. Davidson, E. Stratford, J. Middleton, A. Plyushteva, H. Fitt, S. Cranston, P. Simpson, H. Delaney, K. Evans, A. Jones, J. Kershaw, N. Williams, D. Bissell, T. Duncan, F. Sengers, J. Elvy \& C. Wilmott. 2016. Co-Producing Mobilities: negotiating geographical knowledge in a conference session on the move. Journal of Geography in Higher Education 40 (3):340-374.

Crang, M. (2010). Making sense: introduction. In The SAGE Handbook of Qualitative Geography, ed. D. DeLyser, S. Herbert, S. Aitken, M. Crang and L. McDowell, 337-340. London, UK: Sage.

Cresswell, T. 2014. Geographies of poetry/poetries of geography. Cultural Geographies 21 (1):141-146.

DeLyser, D. 2010. Writing qualitative geography. In The SAGE Handbook of Qualitative Geography, ed. D. DeLyser, S. Herbert, S. Aitken, M. Crang and L. McDowell, 341-357. London, UK: Sage.

Davies, G. 2010. Where do experiments end? Geoforum 5 (41):667-670.

Dewsbury, J. D. (2010). Performative, non-representational, and affect-based research: Seven injunctions. In The SAGE Handbook of Qualitative Geography, ed. D. DeLyser, S. Herbert, S. Aitken, M. Crang and L. McDowell, 321-334. London: Sage.

Ebbensgaard, C. L. 2015. Illuminights: a sensory study of illuminated urban environments in Copenhagen. Space and Culture 18 (2):112-131.

Edensor, T. 2008. Mundane hauntings: commuting through the phantasmagoric working-class spaces of Manchester, England. cultural geographies 15 (3):313-333. 
2017a. Seeing with light and landscape: a walk around Stanton Moor. Landscape Research, 42 (6):616-633.

2017b. From Light to Dark: Daylight, Illumination and Gloom. Minneapolis, MN: University of Minnesota Press.

Edensor, T. and M. Bille. (2017) “Always like never before”: learning from the lumitopia of Tivoli Gardens, Social and Cultural Geography, Advance online publication:1-22. DOI: 10.1080/14649365.2017.1404120

Edensor, T., \& S. Sumartojo. 2018. Reconfiguring Familiar Worlds with Light Projection: The Gertrude Street Projection Festival. GeoHumanities 4 (1):112-131.

Hawkins, H. 2015. Creative geographic methods: knowing, representing, intervening. On composing place and page. cultural geographies 22 (2):247-268.

Hawkins H., L. Cabeen, F. Callard, N. Castree, S. Daniels, D. DeLyser, H. M. Neely, \& P. Mitchell. 2015. What Might GeoHumanities Do? Possibilities, Practices, Publics, and Politics, GeoHumanities 1 (2):211-232.

Isenstadt, S., M. Petty, and D. Neumann. 2015. Cities of Light: Two Centuries of Urban Illumination, London, UK: Routledge.

Kumar, A. 2015. Cultures of lights. Geoforum 65:59-68.

Last, A. 2012. Experimental geographies. Geography Compass 6 (12):706-724.)

Latham, A. 2003. Research, performance, and doing human geography: some reflections on the diary-photograph, diary-interview method. Environment and Planning A 35 (11):19932017.

Latham, A., \& D. McCormack. 2009. Thinking with images in non-representational cities: vignettes from Berlin. Area 41 (3):252-262.

Lorimer, H. 2007. Cultural geography: worldly shapes, differently arranged. Progress in Human Geography 31 (1):89-100.

Madge, C. 2014. On the creative (re)turn to geography: Poetry, politics and passion. Area 46 (2):178-185.

Magrane, E. 2015. Situating geopoetics. GeoHumanities 1 (1):86-102.

Massumi, B. 2002. Parables for the virtual: Movement, affect, sensation. Durham, NC \& London, UK: Duke University Press.

McCormack, D. 2008. Engineering affective atmospheres on the moving geographies of the 1897 Andrée expedition. Cultural Geographies 15 (4):413-430.

2014. Refrains for moving bodies: Experience and experiment in affective spaces. Durham, NC \& London, UK: Duke University Press.

Morris, N. 2011. 'Night walking: darkness and sensory perception in a night-time landscape installation', Cultural Geographies 18 (3):315-342

Ngai, S. 2012. Our Aesthetic Categories: Zany, Cute, Interesting. Cambridge, MA: Harvard University Press.

Rose, M. 2016. A place for other stories: Authorship and evidence in experimental times. GeoHumanities 2 (1): 132-148.

Rose-Antoinette, R. 2015. If the earth is the pedagogy.... Inflexions - A Journal For Research Creation (8):116-129.

Roy, M., \& A. G. Roy. 2018. The Production of Alternative Global Spaces: Walking in the City in Salman Rushdie’s Novels. GeoHumanities 4 (1):66-79. 
Pink, S., P. Hubbard, M. O'Neill, and A. Radley. 2010. Walking across disciplines: from ethnography to arts practice. Visual Studies 25 (1):1-7.

Pink, S., \& S. Sumartojo. 2017. The lit world: Living with everyday urban automation. Social \& Cultural Geography 19 (7):833-852.

Philo, C. 2017. Squeezing, Bleaching, and the Victims’ Fate: Wounds, Geography, Poetry, Micrology. GeoHumanities 3 (1):20-40.

Sedgwick, E. K. 2003. Paranoid Reading and Reparative Reading, or, You're so Paranoid, You Probably Think This Essay is About You. in Touching Feeling: Affect, Pedagogy, Performativity, ed. E. K. Sedgwick, and A. Frank, 123-151. Durham, NC \& London, UK: Duke University Press.

Springer, S. 2017. Earth writing. GeoHumanities 3 (1):1-19.

Stengers, I. 2005. The cosmopolitical proposal, In Making Things Public, ed. B. Latour \& P. Weibel, 994-1003. Cambridge, MA: MIT Press.

Stewart, K. 2007. Ordinary affects. Durham, NC \& London, UK: Duke University Press.

2008. Weak theory in an unfinished world. Journal of Folklore Research 45 (1):71-82. 2011. Atmospheric attunements. Environment and Planning D: Society and Space 29 (3):445-453.

2012. Precarity's forms. Cultural Anthropology 27 (3):518-525.

Swanton, D. 2010. Sorting bodies: race, affect, and everyday multiculture in a mill town in northern England. Environment and Planning A 42 (10):2332-2350.

Williams, N. 2016. Creative processes: From interventions in art to intervallic experiments through Bergson. Environment and Planning A 48 (8):1549-1564.

Wilson, H. F. 2017. On geography and encounter: Bodies, borders, and difference. Progress in Human Geography 41 (4):451-471.

Wylie, J. 2005. A single day's walking: narrating self and landscape on the South West Coast Path. Transactions of the Institute of British Geographers 30 (2):234-247.

2009. Landscape, absence and the geographies of love. Transactions of the Institute of British Geographers 34 (3):275-289. 


\section{AUTHOR BIOS}

Author 1 Vickie Zhang (School of Geography, The University of Melbourne)

VICKIE ZHANG is a PhD student in the School of Geography, The University of Melbourne, Melbourne, VIC 3053, Australia. Email: vzhang@student.unimelb.edu.au. Her research explores themes of relation, intersubjectivity and negativity alongside a focus on working-class life, with interests in affect, mobilities and post-phenomenology.

Author 2 David Kelly (HOME Research Hub, Deakin University)

DAVID KELLY is a research fellow in the HOME Research Hub, Deakin University, Geelong, VIC 3220, Australia. E-mail: david.kelly@deakin.edu.au. His research focusses on home, difference, settler-colonialism and place.

Author 3 Laura Rodriguez Castro (Griffith Centre for Social and Cultural Research, Griffith University)

LAURA RODRIGUEZ CASTRO is a resident adjunct research fellow in the Griffith Centre for Social and Cultural Research, Griffith University, QLD 4218, Australia. E-mail: laura.rodriguezcastro@alumni.griffithuni.edu.au. Her research focuses in the intersections of decoloniality, feminisms and rurality.

Author 4 Tim Edensor (School of Geography, The University of Melbourne \& School of Science and The Environment, Manchester Metropolitan University)

TIM EDENSOR is a research scholar in the School of Geography, The University of Melbourne, Melbourne, VIC 3053, Australia. Email: t.edensor@mmu.ac.uk. His research interests include national identity, tourism, ruins, mobilities and landscapes of illumination and darkness. Amongst other books, he is the author of Industrial Ruins: Space, Aesthetics and Materiality (Berg, 2005) and From Light to Dark: Daylight, Illumination and Gloom (Minnesota, 2017). He is currently working on a project about urban materiality and the city.

Author 5 Michele Lobo (Faculty of Arts and Education, Deakin University)

MICHELE LOBO is a social and cultural geographer in the Faculty of Arts and Education, Deakin University, Burwood VIC 3125, Australia. Email: michele.lobo@deakin.edu.au. Her research interests include race, affect, encounter and co-belonging in cities. She serves as editor for the journal of Social \& Cultural Geography and Book Review editor, Postcolonial Studies Journal. She has held several prestigious grants that focus on Indigenous-ethnic minority encounters, urban Islam and Australia-India student mobility. 
Author 6 Elizabeth Adamczyk (School of Environmental and Life Sciences, University of Newcastle)

ELIZABETH ADAMCZYK is a PhD candidate in the School of Environmental and Life Sciences, University of Newcastle, Callaghan NSW 2308, Australia. Email: elizabeth.adamczyk@newcastle.edu.au. Her research explores skyscraper geographies, in particular how architectural policy is problematised and practised in the pursuit of global urban competitiveness in Sydney, Australia.

Author $7 \quad$ Kaya Barry (Griffith Centre for Social and Cultural Research, Griffith University)

KAYA BARRY is a Postdoctoral Research Fellow in the Griffith Centre for Social and Cultural Research, Griffith University, Nathan, QLD 4111, Australia. Email: k.barry@griffith.edu.au. Her research traverses cultural geography and creative arts, focusing on the intersections of mobilities, creativity, and materiality. Research interests include: mobilities, tourism, migration, more-thanhuman, practice-based research methods.

Author 8 David Bissell (School of Geography, The University of Melbourne)

DAVID BISSELL is an associate professor and Australian Research Council Future Fellow in the School of Geography, The University of Melbourne, Melbourne, VIC 3053, Australia. Email: david.bissell@unimelb.edu.au. His research combines qualitative investigations of embodied practices with social theory to explore the social, political and ethical consequences of mobile lives.

Author 9 Caitlin Buckle (School of Humanities and Languages, University of New South Wales)

CAITLIN BUCKLE is a PhD candidate in the School of Humanities and Languages, The University of New South Wales, Kensington, NSW 2052, Australia. Email: c.buckle@unsw.edu.au. Her research is interested in residential mobility and migration, and the various factors that influence housing and locational decision-making. More specifically, she is interested in finding new ways to map, visualise and understand housing mobility through qualitative GIS and digital methods.

Author 10 Louise Bérénice Dorignon (School of Geography, The University of Melbourne \& Université Lumière Lyon 2)

LOUISE BÉRÉNICE DORIGNON is a PhD student in the School of Geography, The University of Melbourne, Melbourne, VIC 3053, Australia, and Université Lumière Lyon 2, Lyon 69007, France. Email: 1.dorignon@student.unimelb.edu.au._Her research explores the micro-politics of high-rise living, social class relations in housing and suburban change. She is currently developing a critical and in-depth approach to the vertical dimension of urbanisation. 
Author 11 Ainsley Hughes (School of Environmental and Life Sciences, The University of Newcastle)

AINSLEY HUGHES is a PhD candidate in the School of Environmental and Life Sciences, University of Newcastle, Callaghan NSW 2308, Australia. Email: ainsley.hughes@uon.edu.au. Her research interests are in emotion, affect, technologies and mobilities. Her current research project explores the meaning of 'being lost' with respect to contemporary practices and politics of everyday wayfinding.

Author 12 Benjamin Lucca Iaquinto (Department of Geography, The University of Hong Kong)

BENJAMIN LUCCA IAQUINTO is an Assistant Professor in Tourism in the Department of Geography, University of Hong Kong, Hong Kong. Email: iaquinto@hku.hk. His research interests include mobilities, sustainable tourism and backpackers. Forthcoming research projects examine how the Chinese tourism industry could reduce its carbon footprint and better adapt to a changing climate.

Author 13 Melissa Kennedy (School of Humanities and Social Sciences, La Trobe University)

MELISSA KENNEDY is a lecturer in the School of Humanities and Social Sciences, La Trobe University, Bundoora, VIC 3083, Australia. Email: m.kennedy@latrobe.edu.au. Her research interests are in community planning and human geography, specialising in community economic development. Her interdisciplinary research focuses on community economies and rural regeneration including: community activism, commoning and cultural and creative economies including local food and festivals.

Author 14 Cambpell McKay (Pangea Research Centre, University of New South Wales)

CAMPBELL MCKAY is a PhD candidate in the Pangea Research Centre, The University of New South Wales, Kensington, NSW 2052, Australia. Email: campbell.mckay@unsw.edu.au. His research seeks to explore the intersections between militarisation, trauma and place. Since 2014, Campbell has been investigating the construction of contemporary Viêt Nam as a landscape of care for Australian Vietnam War veterans, and the subsequent development of related trauma cultures in the city of Vũng Tàu.

Author 15 Charishma Ratnam (School of Humanities and Languages, University of New South Wales)

CHARISHMA RATNAM is a PhD candidate in the School of Humanities and Languages, The University of New South Wales, Kensington, NSW 2052, Australia. Email: c.ratnam@unsw.edu.au. Her research with Sri Lankan refugees seeks to investigate their use of 
the home during settlement in Sydney. Charishma uses ethnographic and mobile methods to better understand place-based experiences, encounters and practices.

Author 16 Peta Wolifson (School of Humanities and Languages, University of New South Wales)

PETA WOLIFSON is a human geographer based in Sydney, Australia. Email: petaw@unsw.edu.au. Her research specialises in the urban night. She holds a PhD from The University of New South Wales and is interested in the discursive relationships between governance, media and activism in relation to urban social justice.

\section{FIGURES}

FIGURE ONE CAPTION: Taken by David Kelly

FIGURE TWO CAPTION: Taken by Elizabeth Adamczyk

FIGURE THREE CAPTION: Taken by Vickie Zhang

FIGURE FOUR CAPTION: Taken by Kaya Barry 